\title{
دور المؤسسات المالية الدولية في مكافة الفساد
}

\section{العراق أموذجا}

أ.م.د. محمد حسن خمو، كلية العلوم السياسية، جامعة دهوك ، أقليم كوردستان - العراق ، وزائر في جامعة نوروز

م.م. دلير اساعيل احم، كلية العلوم الانسانية ، جامعة دهوك، اقليم كوردستان- العراق ، وزائر في جامعة نوروز

أن اساءة استخدام السلطات التي يعبر عنها (بالفساد) في الاصل هي مسألة داخلية تتولى الدول حمة مواجتها والحد منه بموجب قوانيها الداخلية إلا أن هذه الظاهرة بعد أن توسعت وانتشرت بشكل كبيرة بحيث أصبحت ذات سمة عالمية عابرة للحدود، بدأت تستقطب اهتمام المؤسسات المالية الدولية ، لذلك بدأت هذه المؤسسات ( البنك الدولي ، وصندوق النقد الدولي، ومجموعة العمل المالي الدولية ) باعتاد سياسات واستراتيجيات ، تجسدت الغاية منها على الاقل وفق ما هو معلن بتقديم الدع والمساعدة المى اعضاء الجمتمع الدولي بقصد القضاء على ظاهرة الفساد او على الاقل

يوصف الفساد بأنه مشكلة العصر وسبباً في تأخر الدول ودمارها، هذه المشكةة 2.1 اشكالية موضوع البحث التي لم تسلم منها اية دولة من الدول مهاكان درجة تقدما السياسي والاقتصادي تدور اشكالية البحث حول ايجاد اجوبة مناسبة للتساؤلات الآتية: ماهي اهم العوامل والأسباب التي تساعد على تفشي ظاهرة الفساد. والاجتماعي والثقافي ، والمعروف أن الفساد له صور واشكال متعددة، وأن هناك ما هو الدور الذي تمارسه المؤسسات المالية الدولية في مكافة الفساد ؟. هل الاستراتيجيات الخاصة بالفساد والتي تضعها المؤسسات المالية الدولية

كافية في حال اعتمادها من قبل الدول في القضاء على ظاهرة الفساد ؟.

\section{1 فرضية البحث}

لابد لكل بحث من فرضية ينطلق منها الباحث ويحاول اثباتها ، وفرضيتنا في هذا البحث هي ان الجهود المبذولة من قبل المؤسسات المالية الدولية لها دور كير في مجال مكافة الفساد وذلك لان هذه المؤسسات وخاصة ( البنك وصندوق النقد الدولي ) غالباً ما تربط مساعداتها المالية بشروط الغالب الوع منها يتمثل في ضرورة قيام الدولة بمكفة الفساد لديها ، الا أن عدم وجود الرقابة الفعالة من قبل هذه المؤسسات على الدول الي تتلقى المساعدات من قبلها افقد جهودها الكثير من عوامل مختلفة تساهم بشكل أو بآخر في تفشي هذه الظاهرة ، ولأن الفساد قد بات ظاهرة عالمية عابر للحدود، فقد أصبحت هذه الظاهرة محل اهتمام المؤسسات المالية الدولية (البنك وصندوق النقد الدولي وبموعة العمل المالي الدولية) حيث عملت هذه المؤسسات على ايجاد الاستراتيجيات والأساليب والوسائل التي يكن من خلالها مساعدة الدول في القضاء على هذه الظاهرة او على الاقل الحد منها، وبقصد توضيح مضامين بحثنا هذا فقد اثتملت المقدمة على الفقرات المدرجة ادناه:

\section{1}

تكمن اهمية كبيرة جدا وتتمثل هذه الأهمية في كونه يتطرق الى دور اهم المؤسسات المالية الدولية في مكافة الفساد ، حيث يتصدى البحث بعد أن جزت الجهود على المستوى الداخلي للدول في مكافة الفساد او الحد منه ، يتصدى المى مدى جدوى وفعالية دور المؤسسات الدولية المالية في القضاء على هذه الظاهرة التي لا تكاد تسلم منها اي دولة من الدولة محاكانت درجة تقدما واينا رسمت حدودها في

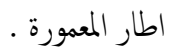


هذا والى جانب تعاريف اللغة مُمة تعاريف اخرى البعض منها فقهي والبعض الآخر هو نتاج الجهود الدولية فعلى الصعيد الفنهي تم تعريف الفساد بأنه (( بموعة من الأعمال الخخالفة للقوانين والهادفة إلى الثأثير بسير الادارة العامة أو قراراتها أو

$$
\text { انشطتها بهدف الاستفادة المالية او الانتفاع غبر المباشر)(2) }
$$

وهناك من عرف الفساد بانه قيام الموظف بإساءة استعال السلطة العامة

الممنوحة له لكسب من اجل تحقيق مصلحته الشخصية (3). وعرف البض الاخر الفساد بالقول (( انخراف سلوك الفرد عن الطريق او المسار الصحيح مما يؤدي الى الحاق الضرر بالمال العام او بالمصلحة العامة من خلال أداء واجب رسمي في وظيفة عامة لتحقيق منافع و مصاح شخصية

$$
\text { (4) }(() \text { ب. }
$$

ويذهب البعض الآخر في تعريف الفساد الى انه (كل عمل غير قانوني ماديا واخلاقيا من جانب العاملين يسود في بيئة بيروقراطية وبهدف إلى تحقيق مصاح شخصية على حساب المصلحة العامة، مما يؤدي الى صدر في موارد الدولة الاقتصادية والاجتاعية ويؤدي المى عدم الاستقرار السياسي(5). ويعرف الفساد ايضا بانه (( السلوك المنحرف عن الواجبات الرسمية محاياة لاعتبارات خاصة كالأطاع المالية والمكلسب الاجتاعية وارنكلب مخالفات ضد

$$
\text { القوانين لاعتبارات شخصية)( ) (6). }
$$

ويعرف البعض الاخر الفساد بأنه (سوء استخدام اطراف حكومية أو موظفين حكوميين للمناصب والموارد العامة أو استخدامحا لأشكال غير شرعية من النفوذ

$$
\text { السياسي)(7) }
$$

ويعرف الدكتور بو نعامة الفساد بقوله : ينصرف مفهوم الفساد في الحياة العامة الى استخدام السلطة العامة أو المنصب العموي من اجل تحتيق مكسب خاص او ريح شخصي او من اجل تحقيق هيبة او مكانة اجتاعية او من اجل تحقيق منفعة

لجماعة بالطريقة التي يترتب عليها مخالفة التشريع ومعايير السلوك الأخلاقي (8). هذا على صعيد الفقه أما على صعيد الجهود الدولية ، فقد عرف البنك الدولي الفساد بأنه ( اساءة استعال الوظيفة العامة لكسب خاص) (9). وعرف صندوق النقد الدولي الفساد بأنه ((علاقة الايدي الطويلة المتعمدة التي تهدف إلى الاستفادة من السلوك الصادر من شخص واحد او مجموعة من الأشخاص ذات علاقة بالأخرين (10). والملاحظ على اتفاقيات الأم المتحدة ملكافة الفساد الاداري والمالي لعام (2003) والتي دخلت هيز النفاذ عام ( 2005) انها امتنعت على ايراد تعريف للفساد
4.1 منهجية البحث

اعتمدنا في هذا البحث على المنهج الاستنباطي التحليلي والذي يعول على تحليل الاستراتيجيات التي تم وضعها من قبل المؤسسات المالية الدولية بقصد التوصل الى تمديد فعاليتها في مجال مكافة الفساد بكافة صوره واشكلله .

5.1 المعروف أن ظاهرة الفساد قد حظيت باهمام كافة المنظمات الدولية ( العالمية منها والوقليمة) كالأم المتحدة والتحاد الأوربي وغير هها من المنظمات ، ال اننا ارتأينا في اطار هذا البحث التطرق الى دور المؤسسات المالية المتخصصة في مكافحة ظاهرة الفساد ، اما بهود بقية المنظلات فأها تخرج من نطاق دراستنا .

\section{1}

لغرض الإحاطة بمفردات البحث من جوانبه كافة فقد تم تقسيمه الى مبحثين، حيث خصصنا المبحث الأول لمفهوم الفساد وقد قسمنا هذا المبحث على ثلاثة مطالب، تناولنا في الأول تعريف الفساد، اما المطلب الثاني فقد تطرقنا فيه الى انواع الفساد، اما المطلب الثالث والاخير فقد بينا فيه اسباب الفساد ، اما المبحث الثاني فقد خصصناه لبيان دور المؤسسات المالية الدولية في الحد من ظاهرة الفساد، وتم تقسيمه على ثلاثة مطالب، الأول تناولنا فيه دور البنك الدولي. أما المطلب الثاني فقد خصصناه لدور صندوق النقد الدولي ،أما المطلب الثالث والاخير فقد تطرقنا فيه لدور مجموعة العمل المالم الدولي .

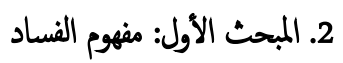
تعد ظاهرة الفساد سمة تلازم كافة المجتمات بغض النظر عن مستوى تقدها

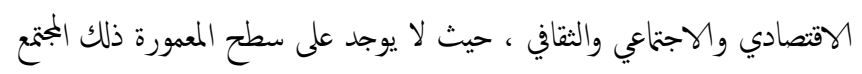
الفاضل الذي يخلوا تماما من هذه الظاهرة ، نخن وبقصد اعطاء تصور واضح عن الفساد من حيث التعريف وانواعه وبيان اسبابه ، قسمنا هذا المبحث الى ثلاث

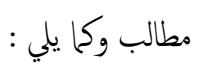
1.2 المطلب الأول: تعريف الفساد

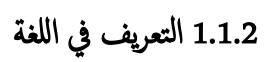
يطلق مصطلح الفساد في اللغة ويراد به نتيض الإصلاح ، والفساد في اللغة هو البطلان ايضا فيقال فسد الثيء اي بطل واضحل ، ويقال تفاسد القوم ، اي تدابروا وقطعوا الأرحام ، والمفسدة خلاف المصلحة (1)

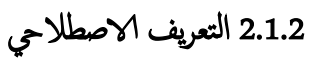


ويتخذ الفساد الاقتصادي صور واشكل متعددة كلمصول على الرشوة أو العمولات مقابل تقديم خدمة او عرض عقود المشتريات والخدمة الحكومية أو انشاء معلومات عن فكرة العقود، او المساعدة على التهرب من دفع الضرائب والرسوم الحكومية وغيرها من

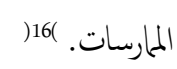
ومما لاشك فيه أن المعادلة اعلاه منطقية إلى حد الاججاع، فما لاشك فيه أن انخفاض دخل ورواتب الموظفين بحيث يكون دون مستوى اشباع حاجاته يعتبر السبب الرئيي والأساسي في انتشار ظاهرة الفساد الاداري، داخل دوائر

$$
\text { ومؤسسات الدولة }
$$

3.2.2 الفساد الإداري

وهو الفساد الككثر انتشارا وغالبا ما يطلق على غالبية صور الفساد بالفساد الاداري، والفساد الاداري تحديدا هو نناج ضعف الاظمة والاجراءات الإدارية في المؤسسات الحكومية وتوارث استخدام الأنظمة البيروقراطية والروتينية ونظام التعقيدات دون اللجوء إلى برامج الإصلاح الإداري الحديثة والابقاء على هذه

السياسات القديمة مع بروز ظاهرة المحسوبية والمحسوبية وغياب الشفافية. (17) وتجدر الاشارة الى انه الفساد الاداري يعود سببه في بعض الاحيان الى وجود قيادات غير ماهرة وقصور سياسات الاجور عن توفير الحد الأدنى لمستلزمات العيش مما يحدو بالموظف العام الى التلكؤ في انجاز المعاملات مما يؤدي إلى اضطرار المراجعين لاتباع اساليب ملتوية وغير مباشرة لتقديم الرشاوي للموظفين بغية تمشي معاملاتهم في الوقت الذي يرى الموظف الصغير بان موظفي الحكومة

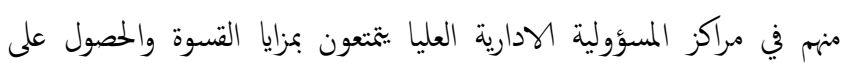
امتيازات شخصية في الدول بشكل قانوني.18) . ونن على يقين أن المزايا الكثيرة والمتنوعة التي يحصل عليها اصحاب المناصب لئب المرموقة وهالة العوز المتحققة في الوقت نسه لدى اصحاب المناصب الصغيرة (الموظف العادي) هي السبب الرئسي الذي يؤدي إلى انتشار ظاهرة الفساد الاداري.

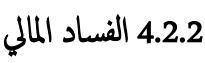
يتمثل الفساد بمجمل الانحرافات المالية وخخالفة الأحكام والقواعد المالية التي تنظم سير العمل الاداري في الدولة ومؤسساتها ومخالفة التعليمات الخاصة بأهزة سير الرقابة المالية كالجهاز المركزي للرقابة المالية المختص بفحص ومراقبة حسابات
متعذرين بالقول أن وضع مثل هذا التعريف غير مككن وغير ضروري وانما اعمدت الاتفاقية توصيفا خاصا للأعمال التي تعد سلوكا فاسدا في الوقت الحاضر تاركا لدول الاعضاء ان تتصرف في امكانية معالجة اشكلال اخرى من الفساد قد تنشأ في المستقبل (11). والواضح ما أوردنا اعلاه أن الفساد يتحقق عندما يقوم موظف بقبول رشوة بقصد تسهيل عقد الشخص اخر ، كما يحدث الفساد عندما يقوم وكلاء أو وسطاء الشركات بتقديم الرشاوى للاستفادة من سياسات او اجراءات عامة للتغلب على المنافسين وتحقيق ارباح خارج اطار القوانين المنظمة للعمل، فضلا عن قيام اصحاب النفوذ والسلطة باستغلال ونهب الأموال العامة للشعب لمصلحته الشخصية (12) وعليه واستنادا إلى ما تقدم يككن تعريف للفساد بانه ((كل استغلال للوظيفة العامة أيا كانت وسيلة الاستغلال بهدف تحقيق مصلحة أو منفعة شخصية)) . 2.2 المطلب الثاني: انواع الفساد يتخذ الفساد صورا"، وأشكلا" متعدد سنشير في هذا المطلب الى اهها، والتي

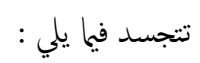

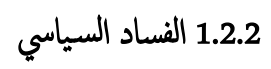
ويتمثل هذا النوع من الفساد بقيام اصحاب المناصب السياسية باستغلال السلطة الممنوحة لمم من اجل تحقيق مصلحة شخصية(13). ويتخذ الفساد السياسي صور عدة أهما ما يلي (14): فساد القمة وهو من اخطر انواع الفساد وترجع خطورته المى ارتباطه بقمة الهرم السياسي في كثير من اشكل النظم السياسية لانتفاع من يتولى القمة بالخروج عن حكي القانون بالمكاسب الشخصية التي تجنهم الثروات الطائلة.

$$
\text { فساد الهيئات التشريعية والتنفيذية. }
$$

الفساد السياسي عبر شراء الاصوات وتزوير الانخابات وفساد الأحزاب السياسية وقضايا التمويل.

يرى بعض العلماء انه اذاكان دخل الفرد مرتفعا ومتساويا مع الأسعار السائدة فان ذلك سيؤدي الى إنباع حاجاته ومن ثم يقلل من اندفاعاته نخو الانخراف، اما اذا كان دخل الفرد منخفضا او منعدما فأنه سيحاول دون شك اشباع حاجاته بأي وسيلة كانت ولو كانت بطريقة غير مشروعة. (15) 
بدوره عاملا مشجعا على صورة معينة للفساد ويتجلى ذلك في جرائم الاختلاس

$$
\text { الكبيرة وتقاضي العملات . (23) }
$$

وغسل الأموال(24) وتجدر الاشارة الى انه من الاسباب الاقتصادية للفساد، تدخل الحكومة في الأنشطة الاقتصادية، كفرض القيود على الاستيراد ومنح الإعانات الحكومية لبعض الصناعات التي تتناج الى دع من قبل الحكومة والنحكم في الاسعار وتعدد انظمة الصرف الأجنبي الامر الذي يؤدي الى دفع الرشاوي الى المسؤولين للحصول على رخص الاستيراد أو الهانات او النقد الأجنبي. (25) فضلا عن تعقد القوانين الضريية وصعوبة فهها ما يجعل هذه القوانين تقبل أكثر من تفسير فيؤد ذلك الى خرق هذه القوانين من قبل مفتشي الضرائب وخصوصا

$$
\text { عند اعطائم سلطة تقديرية في تفسير القوانين. (26) }
$$

كل ما تقدم يعد من العوامل الاقتصادية التي تساعد وبشكل كير جدا في انتشار ظاهرة الفساد الاداري والمالي في كافة الجمتمعات بشكل عام والمجتمعات النامية

$$
\text { بشكل خاص والعراق بشكل اخص. }
$$

3.3.2 الأسباب الادارية للفساد (27) - 3.

تتجسد الأسباب الادارية وتتعلق بالوعي الإداري فكلما كان الوعي الاداري عاليا قلت ظاهرة الفساد والعكس صحيح فكلماكان الوعي الاداري متدنيا زادت نسبة الفساد ، هذا ويتدنى مستوى الوعي الاداري بسبب ضعف القيادات الإدارية وعدم نزاهتها وسوء اختيار العاملين وسوء توزيع السلطات و عدم وضوح التعليمات وسوء تقويم أداء الأفراد والمنظمات (28).... الخ ولاشك اننا في العراق نعيش مستويات متدنية جدا من حيث الوعي كف لا، ونخن نعلم أن معظم القيادات الادارية قد تولت هذه القيادات بطرق واساليب ملتوية وغير شرعية فضلا عن عدم احقيتها في تولي تلك القيادات مما لاشك فيه أن ذلك سيكون له تأثيرا سلبيا على البيئة الادارية وبالتالي انتشار ظاهرة الفساد بشكل كير جدا، وهذا ما يعيشه العراق اليوم باحتلاله مركزا متقدما بين الدول المعروفة بالفساد.

\subsection{2 الاسباب الاجتاعية}

يككن لظاهرة الفساد الاداري ان تتفشى وتتزايد بسبب العوامل الاجتاعية الضارة في بية وتكوين المجمعات البشرية والقيم السائدة فها اذ تؤدي العادات والتقاليد والاعراف دورا محا في نمو هذه الظاهرة فالأصل أن الفساد هو احد الاعراض التي تشير المى وقوع خلل في الشق العام (الجمتع) وبالتالي حدوث خلل في منظومة السلوك والتصرفات التي تنتج عن تراجع قواعد الأخلاق والقيم لدى المعتمين،
واموال الحكومة والهيئات والمؤسسات العامة والشركات، ويكن ملاحظة الفساد المالي في ( الرشوة الاختلاس، والتهرب الضريبي والجمركي .........أخ) (19.. تجدر الاشارة الى ان الصور التي أوردناها اعلاه هي بعض صور الفساد ، فألى جانب تلك الصور ثمة صور اخرى للفساد منها الفساد الأخلاقي والصحي والثقافي والقانوني... الخُ.

3.2 المطلب الثالث: اسباب اتثشار ظاهرة الفساد (20) احتدم النقاش وثار الخلاف بين الفقهاء حول الأسباب التي أدت إلى انتشار ظاهرة الفساد الاداري والمالي ويذهب غالبية الباحثين والفقهاء والأكادييين المختصين بشؤون الفساد الى ان اهم الوسباب التي تؤدي الى ظهور هذه الظاهرة

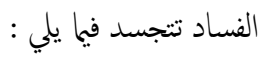

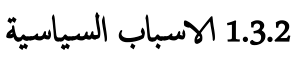

وتتجسد هذه الاسباب في غياب قيم الشفافية والنزاهة والمساءلة وسيادة القانون وهي قيم ترتبط ارتباطا وثيقا بالديمقراطية كثقافة مجتع. ويرى البعض أن محدودية قنوات التأثير غير الرسمية على القرارات الادارية اضافة الى ضعف العلاقة ما بين اللدارة والمجهور وانتشار الولاءات الجزئية كل هذه تئه الحالات من شأنها آن تؤدي المى بروز الفساد الاداري والمالي. فضلا عما تقدم فان هناك عوائق قانونية وسياسية تحول دون توقيع العقوبات على الممتدين وبالتالي فهي تساعد على تفشي ظاهرة الفساد بشكل او باخر كالمصانات التي يتتع بها اعضاء السلطة الادارية والسياسية، اذ غالبا ما تستخدم هذه الحصانات خلال الغرض الذي خصصت له وتصبح وسيلة للنخلص من الملاحقة القضائية عن الانتهات التي يرتكها الموظف وخاصة جرائم الفساد، كما يؤدي ضعف الحكومة إلى عدم استقرار البيئة القانونية والتثريعية التي تحكم المؤسسات الحكومية اذ يجعلها غير قادرة على تطبيق القوانين التي تحد من انتشار الفساد واتخاذ الإجراءات القانونية تجاه المفسدين ومعاقتهم. (22)

2.3.2 الاسباب الاقتصادية يلعب هذا العامل دورين في تحقيق وانتشار ظاهرة الفساد من حيث الفقر والفنى، فالفقر عامل يصعب احيانا انكار صلته بالفساد على الأقل في بعض صوره لاسيا في رشوة صغار الموظفين من ذوي الدخول المتواضعة، أما الغنى فيبدو 
يضطلع به ادارة العمليات الإقليمة بالبنك والادارة المعنية بتخفيض أعداد الفقراء وادارة الشؤون الاقتصادية ومعهد البنك الدولي والادارة القانونية . (35) ومما لاشك فيه أن الدور الذي يضطلع به البنك الدولي في العمل على تخفيض أعداد الفراء ساهم الى حد ما في القضاء على ظاهرة الفساد على اعتبار أن الفقر المتشثي بين ابناء الشعب العراقي بشكل عام والموظفين بشكل خاص يعد من اهم

$$
\text { الرشاوي وبالتالي انتشار ظاهرة الفساد. }
$$

وتجدر الاشارة الى أن البنك الدولي قد قام بوضع عدة استراتيجيات الهدف منها هو مساعدة الدول على الحد من ظاهرة الفساد بكافة صوره واشكله وقد تضمنت هذه الاستراتيجيات اربع محاور رسمية تنمثل بما يأتي : منع كافة اشكال الاحتيال والفساد في المشروعات الممولة من قبل البنك. اعتبار مكافة الفساد شرطا أساسيا لتقديم خدمات البنك عن طريق

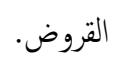

تقديم العون للبلدان النامية (ومن ضمها العراق التي تعتزم مكافة الفساد.

$$
\text { دع الجهود الرامية إلى مكاففة الفساد والحد منه. }
$$

وهذا ويدرك البنك الدولي أن الروابط الفاسدة والسرية بين الحكومة والقطاع الخاص وقطاع البنوك يمكن أن يساهم في انتشار ظاهرة الفساد بشكل كير وان الاصلاحات البنيوية على هذه الأصعدة هي شرط الإطلاق كف بعض المشاريع الحالية، وبالفعل بدأت مشاريع الإصلاح الحكومية من قبل البنك الدولي كجزء من التعديل البنيوي في القروض تصمم لإصلاح السلطات التنفيذية والمؤسسات الضريبية والقضاء وغيرها من مؤسسات الدولة كوسيلة للحد من ظاهرة الفساد(36). ومما لاشك فيه أن العراق بشكل عام واقليم كوردستان بشكل خاص بأمس الحاجة الى اصلاح هذه المؤسسات وخاصة القضاء الذي سيسامي فيا لو تحقق استقلاله الكمل بشكل كير في الحد من ظاهرة الفساد، فضلا عا يقدم البنك الدولي من خلال ادارة النزاهة المؤسسية التابعة لها بعمليات وقائية ضد الفساد، كندريب الموظفين على اكتشاف وردع الاحتيال ،كما تقوم هذه الادارة بوضع خطط لأطلاق برنامج افصاح رسمي طوعي تم تصميمه لتمكين المؤسسات من الابلاغ طوعا عن حوادث الفساد التي تتورط فيها مقابل تحقيق عقوبها ، هذا وقد تمكنت ادارة النزاهة المؤسسية منذ عام 1999 بالتحقيق في (2007) قضية متعلقة بالفساد وفرضت عقوبات على اكثر من 330 شركة وفردا(37). وتجدر الاشارة الى لى أن برنامج الافصاح الطوعي يتميز بالعديد من المزايا فهو يساعد عدد من الدول
بمعنى اخر فالعامل الاجتياعي هو بمموعة من المؤثرات والظروف التي تحيط بالجاني فتجعله يتخذ سلوكا مضادا للمجتمع. (29) وعليه فالمجتع الذي تنتشر فيه القيم والأفكار البالية والقبلية والجهل والتخلف سيسوده وي:تاحه الفساد بشكل كير جدا والعكس صيح وتجدر الاشارة الى انه

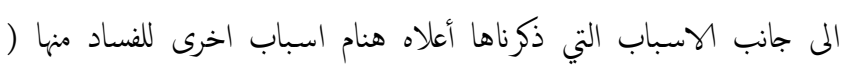
الأسباب القانونية والثقافية، وحضارية وفنية....خ) (30).

\section{3. المبحث الثاني: دور المؤسات المالية الدولية في الحد من ظاهرة الفساد} تختص المؤسسات المالية الدولية في الأصل بالشؤون المالية كتقديم القروض وغيرها من اوجه الدع الملالي للدول، اله انها تمارس دورا محا في الحد من ظاهرة الفساد التي لم تسلم منها اي دولة من الدولة والحديث عن دور المؤسسات المالية الدولية في الحد من ظاهرة الفساد يقتضي منا التطرق الى دور كل من ( البنك الدولي وصندوق النقد الدولي، ومجموعة العمل الملالي الدولية ) ولغرض الإحاطة بالمفردات اعلاه، ارتأيتنا تقسيم هذا المبحث الى ثلاثة مطالب و على النحو الآتي:

\section{3 المطلب الأول: دور البنك الدولي في الحد من ظاهرة الفساد}

أنشي البنك الدولي بموجب اتفاقية ( بريتون ووتز ) لعام 1944، كوسيلة لمساعدة الدول التي تضررت من الحرب العالمية الثانية. و ابتداء أعاله عام 1946 بعد أن صادقت على اتفاقية انشائية (28) دولة وهو العدد المطلوب لدخول الاتفاقية حيز النفاذ.(31) هذا وييلغ عدد الدول الأعضاء في البنك الدولي (183) دولة (32) ومن

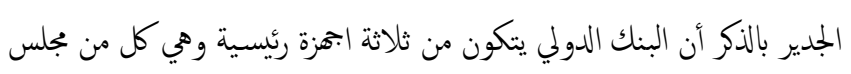
المحافظين، ويتكون هذا المجلس من جميع الدول الأعضاء حيث تقوم كل دولة بتعين محافظ ونائب له مدة خمس سنوات وتتزكز جميع سلطات البنك في هذا الججلس ويعقد الجملس اجتماعاثه مرة واحدة في السنة ومع ذلك يجق المجلس الاجتماع في دورات انعقاد غير عادية كلما تطلب الأمر ذلك. (33) اما الجهاز الثاني الذي يتكون منه البنك فهو مجلس المديرين التنفيذين وهو الجهاز الذي يتولى الإدارة الحتيقية لأعال البنك اما الجهاز الثالث والاخير للبنك فيتثل بالرئيس والذي يتم انتخابه من قبل مجلس المديرين التنفيذيين وهيئة الموظفين بالبنك وهو المسؤول عن أعال البنك وعن تعين الموظفين وفصلهم. (34) اما عن الجهود التي بذلها البنك الدولي في الحد من ظاهرة الفساد في الدول كافة ومن ضنها العراق فهي تتجسد في قيام البنك بتقديم المشورة للبلدان كافة فيا يتعلق بكيفية تحسين شفافية الخدمات العامة والمسائلة من خلال العمل التحليلي والتننيذي الذي 
بمارستها فهو (صندوق النقد الدولي يتولى وظيفة تقديم القروض والمساعدات للدول الأعضاء فيه . وبالتالي فأنه يمارس من خلال هذه الوظيفة دوراً محاً في الحد من ظاهرة الفساد حيث صندوق النقد الدولي بوضع ضوابط تتعلق بتقديم القروض والمساعدات،

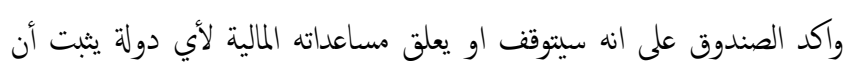

الفساد الحكوي فيها يعيق الجهود الخاصة يتجاوز مشاكلها الاقتصادية (43). هذا ويطرح صندوق النقد الدولي مجالين رئيسين لمساهة في مكافة الفساد، المجال الأول في تطوير ادارة الموارد العامة ويشمل ذلك اصلاح الخزينة ومديرات الضريبة، واسس اعداد الموازنات العامة واجراءات والنظم المحاسبية والتدقيق، أما المجال الثاني فهو خلق بيئة اقتصادية مستقرة وشفافية وبئة اعلال نظامية تشمل تطوير القوانين المتعلقة بالضرائب والأعال التجارية(44). هذا وتجدر الاشارة الى أن صندوق النقد الدولي حدد حالات الفساد بالمارسات المرتبطة بأنفاق الأموال العامة في غير الجمالات المحددة لها وتورط الموظفين الرسمين في عمليات تحايل كركية او ضريبة، واساءة استخدام احتياطي العملات الصعبة من قبل هؤلاء الموظفين واستغلال السلطة من قبل المشرفين على المصارف ، والمارسات الفاسدة مجال تنظيم الاستثمر الأجنبي المباشر ، كما اتخذ الصندوق موقفا حازما من الدول التي تعتبر رشوة الموظفين الحكوميين في الدول الاخرى نوعا من نفقات التزويج للأعال وتستوجب الاعفاء(45). وتتصل إجراءات الصندوق الرامية إلى لى

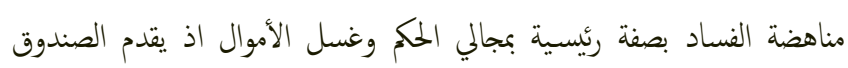
دعمه للسياسات المناهضة لغسل الأموال عبر المساعدة التقنية في تطبيق موحد الاشتراكات التزخيص والابلاغ الملالي عن جميع اشكال معاملات صرف العملات الأجنيبة، واتباع مدونات قواعد السلوك في أسواق صرف العملة واحتواء التهرب الضريبي وكلما يتصل به من غسل عائدات التهرب، أما في مجال الحكم فقد اعتبر

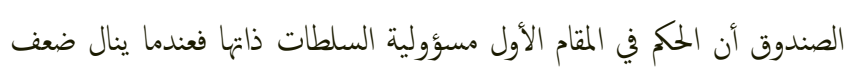
الحكي من قدرة الحكومة على انتهاج سياسات اقتصادية ومالية سلمة، يكون لذلك الك

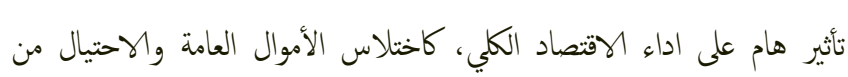
جانب موظفي الضرائب، لذلك فأن الصندوق يقوم بتقديم دعه للدول في سبيل

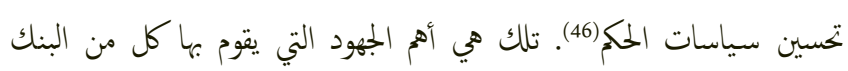

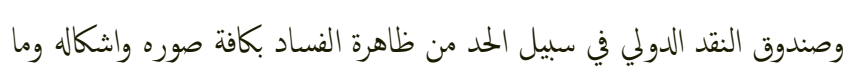
أحوج العراق إلى اعتماد كافة الاستراتيجيات التي أقترها هاتين المؤستين الماليتين كي يتمكن من خلق بيئة عراقية نظيفة إلى حد ما من هذه الأفة ( الفساد التي
الأعضاء على ضمان سلامة استخدام أموال هذه الدول من اتخاذ اجراءات تنفيذية لها مضمونا ومغزاها استنادا إلى عمليات الاقصاح من جانبين المشتركين في

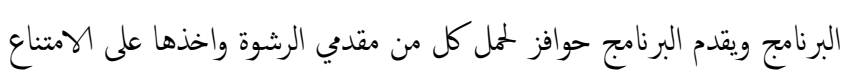
عن اقتراف السلوك الفاسد والامتثال للقواعد والارشادات التي يضعها البنك، كما يعد البرنامج وسيلة متعة بالكفالة لمحاربة الفساد(38.) وبشكل عام يرى البنك

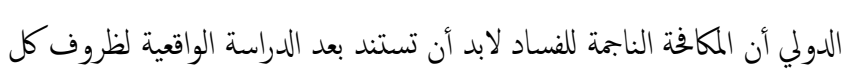
دولة إلى مزيج من برامج الإصلاحات السياسية والاقتصادية والقانونية والادارية وتتضمن تلك البرامج اصلاح الخدمة العامة بزيادة الأجور وتقيد المسوبية السياسية في التوظيف والتزقية واستغلال القضاء، كما نوه البنك الى تقوية اليات الرصد والعقاب المتعلقة بالفساد مع ضان التنفيذ الصارم لقانون العقوبات، اضافة

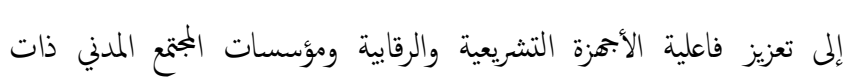
العلاقة(39). وبالتالي يتضح لنا أن البنك الدولي يمارس دورا محا في الحد من ظاهرة الفساد وذلك باعتلاده على سياسة الامتناع عن منح القرض الى الدول التي تشهد ارتفاعا في نسبة هذه الظاهرة (الفساد) حيث أن امتناع البنك عن

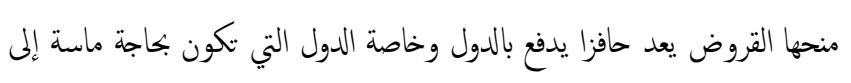

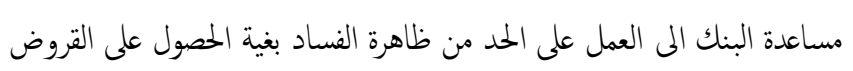
من هذه المؤسسة المالية.

\section{3 المطلب الثاني: دور صندوق الثقد الدولي في الحد من ظاهرة الفساد} صندوق النقد الدولي وهو جهاز بنكي دولي حكوي انشئ بموجب الاتفاقية التي انشأت البنك الدولي (بريتون ووتز) عام 1944، وباشر الصندوق اعاله في عام 1947 وييلغ عدد الأعضاء فيه (183) دولة (40) ـ ويتكون صندوق النقد الدولي شأنه في ذلك شأن البنك الدولي من ثلاث اجهزة رئسية وهي مجلس المديرين التنفيذيين ومدير الحارة(41). اما عن الدور الذي يمارسه صندوق النقد الدولي في مجال الحد من ظاهرة الفساد بكافة صوره واشكاله ، فيتجسد في اعتكف الصندوق على وضع وتنقيح معاير طوعية تتعلق بالمارسات الاصلاحية وبلورة مواثيق تتعلق بالمارسات السلمية في مجال المالية العامة والسياسات النقدية، ويحاول الصندوق في اطار انشطته التي يمارسها لحسن الاضطلاع بوظائفه الخمتلفة الرقابية والاقراضية توجيه سياسات الدول الاعضاء نحو الالتزام بتلك المعايير والمواثيق والتي تساعد في حال الالتزام بها على سد الثغرات امام الفساد(42). هذا والمعلوم أن دور الصندوق النقد الدولي في الحد من ظاهرة الفساد مرتبط ارتباطا وثيق بالوظيفة الأصلية التي يختص 


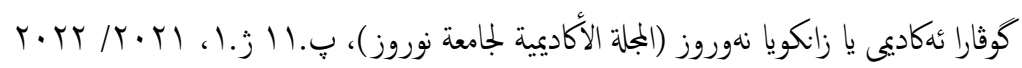

اتفاقية الأم المتحدة لمهافة الاتجار غير المشروع بالمخدرات والمؤثرات العقلية لعام 1988. وعلى كل دولة أن توسع نطاق التجريم ليشتمل على غسل

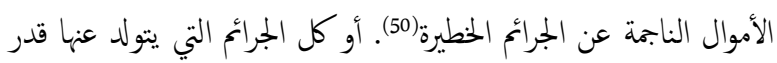

$$
\text { كبير من الإيرادات (51). }
$$

إقامة المسؤولية الجنائية للأشخاص المعنوية في جرائم غسيل الأموال دون الإخلال بالمسؤولية الجنائية للأفراد(53).

رفع السرية عن أعمال البنوك من خلال تشجيع التعاون بين بحات إنفاذ القانون واللوائح من ججة، والمؤسسات المالية من جهة أخرى، وبها التعاون تتم حاية المؤسسات المالية من أية مسؤولية عن إفشاء المملومات إلى رجال إنفاذ القانون ما داموا يعملون بحسن نية(54).

التزام الدول باتخاذ إجراءات مماثلة للإجراءات المنصوص عليها في اتفاقية فيينا للإتجار غير المشروع بالمخدرات 1988، وذلك لتمكين السلطات الختصة بمادرة الممتلكت المغسولة والمتحصلات من غسل الأموال أو الجرائم الأصلية المفضي إلهيا، والمعدات المستخدمة أو المعدة لاستخداهما في ارتكلب الجرائم أو الممتلكات ذات الثيمة المكافئة(55). 5- التزام المؤسسات المالية بعدم فتح حسابات بهولة الهوية أو بأسهاء وههية، والتحقق من هوية العملاء الذين يرغبون في فتح حسابات المصلحة الغير، والاحتفاظ بالقيود وسائر المستندات المتعلقة بالعمليات التي جرت على هذه الحسابات داخل البلاد أو مع الخارج لمدة خمسة سنوات على الأقل، بشكل يجعل المصارف والمؤسسات المالية قادرة على تلبية أي طلب معلومات يردها عند اللزوم من السلطة

$$
\text { المختصة وبالسرعة اللازمة).(56) }
$$

التزام المصارف والمؤسسات المالية بإعلام أو تبليغ السلطات المحلية ذات الاختصاص والصلاحية عن الصفقات المالية المشبوهة أو المشكوك في أنها

$$
\text { تضضمن غسلا للأموال (57). }
$$

التزام المؤسسات المالية بتطوير برامجها لمهلفة جريمة غسل الأموال، وأن تقوم بوضع دليل إرشادي لكي يساعدها في كشف المعاملات المالية

$$
\text { المشبوهة (58). }
$$

انتشرت فيه بشكل مرعب حتى وضعت العراق في مقدمة الدول الحاضنة لهذه الظاهرة. والسؤال الذي يطرح نشه هنا هل ساهم البنك وصندوق النقد الدولي

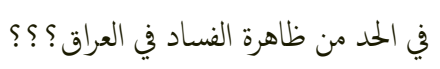
للإجابة على ذلك نول بالرغز من جدوى وفعالية الاستراتيجات والأساليب التي

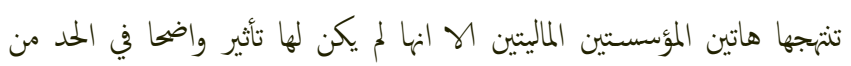
ظاهرة الفساد في العراق ولعل السبب وحسب اعتقادنا يعود الى ربط البنك وصندوق النقد الدولي دورها بالقروض، أي أن كل منها يمتنح عن منح القروض

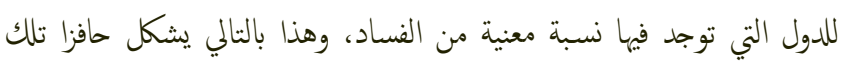
الدول الى التقليل من شبة الفساد التي فيها، والعراق وبسبب الموارد الطبيعية الموجودة فيه وعلى راسها النفط قلة ما يلجا إلى الاقتراض من البنك وصندوق النقد الدولي وهذا بطبيعة الحال يحجب دور المؤسسات المالية محل الدراسة في

$$
\text { الحد من ظاهرة الفساد في العراق. }
$$

\section{3 المطلب الثالث: فرقة العمل الملالي الدولية (FAFT)} تم تشكيل هذه الفرقة بناء على قرار صادر عن مؤتمر القمة للدول الصناعية السبع الكبرى الذي عقد في باريس عام 1989 بدعوة من الرئيس الفرنسي ملهافحة عمليات غسل الأموال وقد أخذت هذه الفرقة على عاتقها منذ تشكيلها ممة القيام بدورين رئيسين ها ، وضع المعايير والتوصيات المتعلقة بكلفة غسيل الأموال ، وتقييم مدى التزام الدول بتطبيق هذه المعايير والتوصيات(45). فعلى صعيد الدور الأول أصدرت هذه الفرقة في 1990/4/19 تقريرا يتضمن (40) توصية خاصة بكافة غنسل الأموال المثأنية من الأنشطة غير المشروعة)47) . ولقد عنيت توصيات منظمة مكافحة غسل الأموال بثلاثة أركان رئسية وهي : إنشاء سياسات وإجراءات خاصة بمفوم (اعرف عميلك) ، وإنشاء نظام خاص بالتسجيل والإبلاغ عن تحويلات المبالغ الكبيرة ، وإيجاد أسلوب للتوفيق بين سياسات البنوك الداخلية وبين ما تتطلبه إجراءات مكاففة العمليات المشبوهة لغسل الأموال(48). وقد أسهمت هذه التوصيات في رسم السياسة الجنائية الدولية

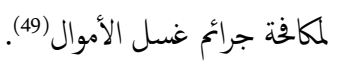
ولعل أهم ما انطوت عليه هذه التوصيات بهذا الخصوص ما يأتي : التزام الدول باتخاذ إجراءات تشريعية تتضمن تجريم غسل الأموال على

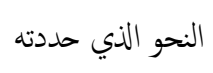


يتخذ الفساد صورا واشكلا متعددة فهناك الفساد السياسي والاقتصادي والاجتاعي والثقافي والمالي... الخ وان هناك بموعة من العوامل والأسباب العامة التي تؤدي الى تفشي هذه الظاهرة. وفي العراق تتجدد اهم تلك الاسباب او العوامل في غياب الأمن وضف ابهزة الرقابة وانخفاض مستوى الدخل (الفقر ) ويمتد ذلك من العوامل التي ساهت وبشكل كير تير في جعل العراق يحتل مراتب متقدمة بين الدول المعروفة بهذه الظاهرة. 3.يمارس صندوق البنك الدولي دورا هما في مكافحة ظاهرة الفساد بكافة صوره واشكلال، وذلك من خلال الاستراتيجيات التي يضعها ومن بين الأساليب التي تتبعها هذه المؤسسات المالية انها تتنع عن تقديم القروض الى اي دولة تكون نسبة الفساد فيها مرتغعة، وهذا بحد ذاته يشكل حافزا يدفع الدول الى أن تضع نصب عينها العمل على الحد من هذه الظاهرة لغرض الاستفادة من الامتيازات التي تقدما المؤسسات المالية الدولية و التي تتجدد في القروض.

نوصي المثرع بضرورة تبني كافة الاستراتيجيات الموضوعة من قبل المؤسسات المالية الدولية (البنك وصندوق النقد الدوليين والموضوعة لغرض مكافة ظاهرة الفساد لما فيها من دور كير في الحد من هذه الظاهرة. نوصي المشرع بضرورة تشديد العقبة المقررة لجريمة الفساد وجعلها مماثلة اللعقبة المقررة للجرائم الماسة بأمن الدول، لأن هذه الجريمة (الفساد) تعتبر بالفعل سببا رئيسيا في انهيار الجمتمعات والدول، وبالتالي تشديد العقوبة الى سلى هذا الحد سيساهم دون شك في ردع كل من سوى له نضه الانجاز بالوظيفة العامة والانحدار بها الى منزلة البضائع. نوصي المشرع بضرورة الأخذ بما يسبب المكومة الاككتونية في مجال التعامل بين الموظفين والمراجعين لأن ذلك يساعد نوعا ما على توسع الفجوة او المسافة بينها مما يقلل الى هد ما من حالات الفساد.

نوصي المثرع بضرورة افساح المجال لمؤسسات المجتع المدني وان يجتضن العراق عددا لابأس به منها فضلا عن ضرورة تفعيل دور الرقابة الشعبية الرامية إلى الحد من ظاهرة الفساد لمال لذلك من دور كمم وفعال في القضاء

$$
\text { على هذه الأفة (الفساد). }
$$

التزام المؤسسات المالية بأن تعهد إلى السلطات الدولية الختصة مثل الانتربول وبجلس النعاون الجمركي مسؤولية جمع المعلومات المتعلقة بآخر تطورات غسل الأموال، وفنون غسلها، وتزويد الدول بها (59.) عقد معاهدات واتفاقيات دولية وثنائية والمصادقة على تشريع وطني يتيح النعاون الدولي السريع والفعال على المستويات كافة (60). تشجيع التعاون بين السلطات المختصة المعنية بكلفة غسل الأموال في البلدان المختلفة في مجال التحقيقات (61). يجب أن تكون هناك مساعدة قضائية متبادلة في مسائل القانون الجنائي.(62) وجوب اتخاذ إجراءات سريعة للرد على طلبات الحكومات الأجنبية الخاصة بتعيين وتجميد ويجز ومصادرة متحصلات الجريمة أو الأموال الأخرى التي تعادل قيمة المتحصلات المستمدة من غسل الأموال أو من الجرائم موضوع

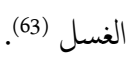
يجب على الدول اتخاذ إجراءات تسمح بتسليم الأفراد المتهمين بجرائم غسل الأموال أو الجرائم المرتبطة بها ـ وعلى كل دولة أن تعد جريمة غسل الأموال من الجرائم التي يجوز تسليم مرتكييها (64). أما على صعيد الدور الثاني فإن هذه الفرقة تقوم بشكل دوري بتقديم تقارير عن مدى التزام الدول بتطبيق هذه التوصيات، ومدى توافق تشريعاتها وممارساتها العملية مع تلك التوصيات (65). فإذا تبين أن هناك خللا أو قصور تصنف الدول القاهرة في قائمة الدول غير المتعاونة في مجال مكافحة غسل الأموال ومن ثخ فإنها تنعرض للعقوبات الاقتصادية (66).

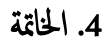
في ختام هذا البحث توصلنا الى مجموعة من النتائُ والتوصيات ستدرجما على

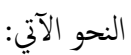
1.4 أن الفتهاء قد اوردوا العديد من التعاريف لظاهرة الفساد ومن خلال جمل تلك التعاريف يكن القول بأن الفساد هو عبارة عن انخراف الشخص الذي يتولى وظيفة معينة بالصلاحيات الممنوحة له من اجل تحقيق مصلحة شخصية لذاته ولغيره. 


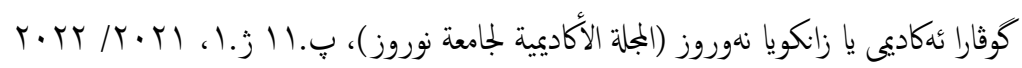

3. سارة بو سعيود ، دور استراتيجية مكافة الفساد الاقتصادي في تختيق التنية

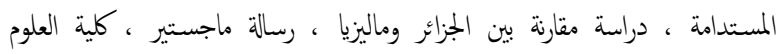

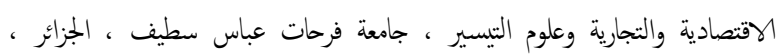

.2013

4. مصطفى حميد كزار ، الفساد الوداري والمالي وانغكاته على البطالة في العراق ، رسالة

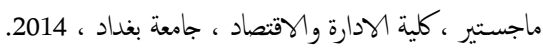

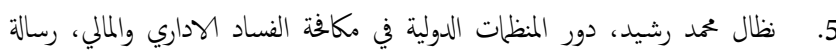

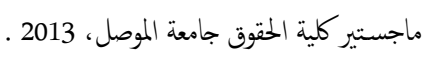
امحمد حسن خمو، دور المنظات المولية في مكلفة الجريمة المنظمة عبر الوطنية، رسالة ماجستير، كلية الحقوق جامعة الموصل، 2010 .

3.5

1. د. داؤود خير الدين ، الفساد كظاهرة عالمية ووسائل ضبطها، حلية المستقبل العربي،

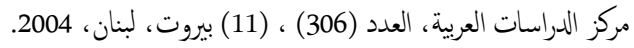

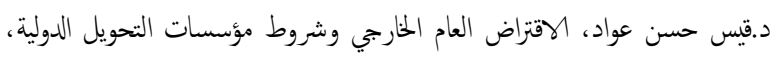

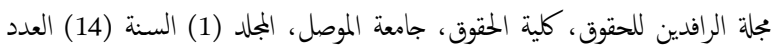
.2009 (40) 3. د. جال داؤود سليمان، الهار الاقتصادية والاجتاعية لظاهرة الفساد الاداري، الجلة. الجامعية الخليجية، المجلد (1)، العدد (4) مملكة البحرين، 2009 ـ 20

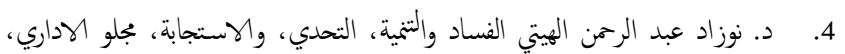
العدد (86) السنة (23) مسقط، عمان، 2001 . 200 5.

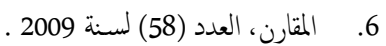
7. السنة الأولى، 2010 .

4.5

1. م. محمد نجدات المحمد ، غسل الأموال في الثريعة الإسلامية ، بحث

منشور على الموقع الآتي: www.kantaksi.com تاريخ الزيارة 12 / 8 /

د. خالد العبيدي ، الواقع التشريعي للجريمة المنظمة عبر الوطنية في العراق ،

$$
\text { مثاح على الموقع الاتي : }
$$

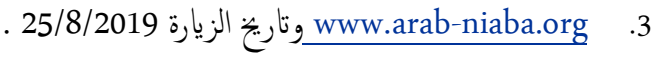

د. مدحت القريشي، الفساد الاداري والمالي في العراق، مقال متاح على

$$
\text { الانترنيت على الموقع الاتي : }
$$

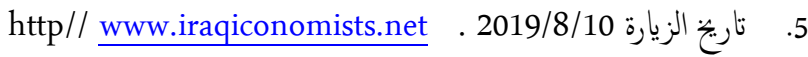

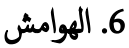

1. جال الدين بن منظور لسان العرب , دار الكتب العلمية , ببروت, 2003 ص 412 - 413 - 413.

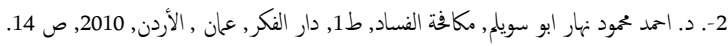

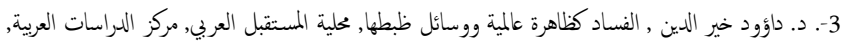

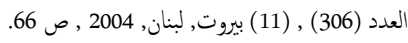

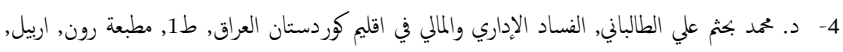
19.1911
1.5

1. امد مهمد خليل ، الجريمة المنظمة، الإرهاب وغسل الأموال ، منشأة المعارف ، الإسكندرية ، 2008.

2. د. صاخ جواد الكاظم ، دراسة في المنظات الدولية ، مطبعة الرشاد ، بغداد، 1975.

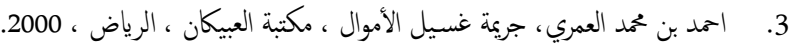
4. 5.

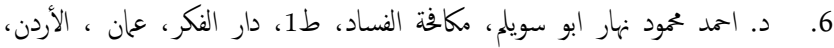
.2010 7. د. أبجد سعود قطيفان ، جريمة غسيل الموال ، دراسة مقارنة ، دار الثقافة للنشر والتوزيع، عان ، الاردن ، 2006 ، 2006

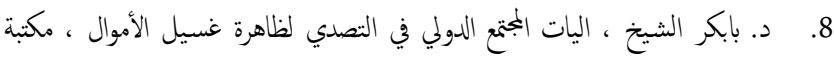

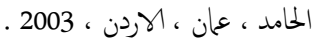

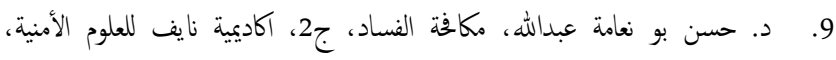
الرياض، 2003

10. د. صلاح الدين فهي مهمود، الفساد الاداري كعوق لعمليات التنمية الاجتاعية

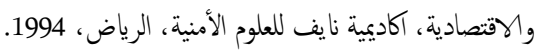

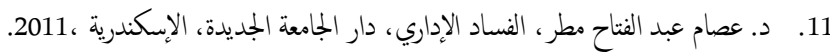

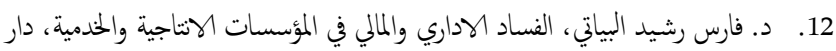
ايلية للنشر والتوزيع، عمان، الأردن، 1. 1. 2010.

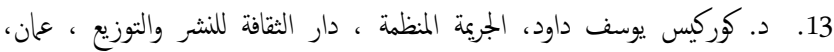

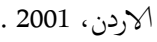
14. د. محمد امين البشرى، الفساد والجريمة المنظمة، اكاديمة نايف للعلوم الأمنية، الرياض،

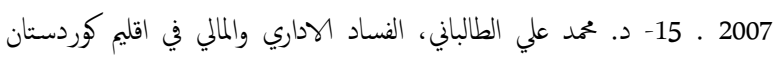
العراق، ط1، مطبعة رون، اربيل 201 15. د. محمد جال، الفساد والحكى الصالخ في البلاد العربية ، مركز الوحدة العربية ، القاهرة ، 2004 16. د. محمود محمد معابرة، الفساد الاداري وعلاجه في الشريعة الاسلامية، ط1، دار الثقافة والنشر، عهان ، الأردن، 2011 و 2. 17. دانا حمه باقي عبد القادر ، السرية المصرفية في إطار تشريعات غسيل الأموال (دراسة

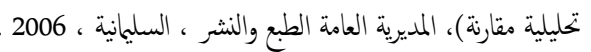

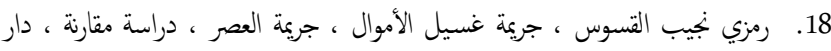

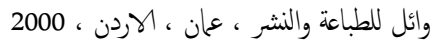

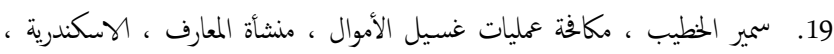

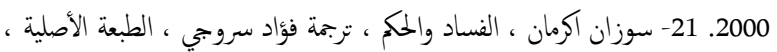

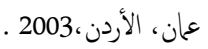

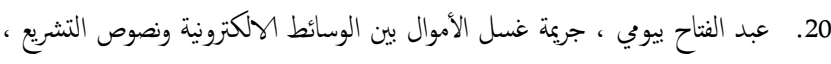
دار الفكر الجامعي ، الإسكندرية ، 2006. 2006.

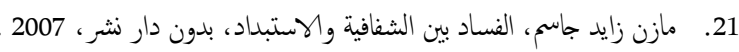

2.5 الرسائل والاطاريح الجامعية

1. ميادة صلاح الدين تاج الدين ، عمليات غسيل الأموال وسبل موابتها من خلال

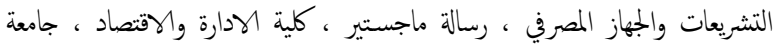
الموصل ، 2005. 2. معن عبد القادر الى زكريا، عولمة المنظات الاقتصادية الدولية وتأثيرها على البلدان النامية، رسالة ماجستير، جامعة الموصل، 2005 . 


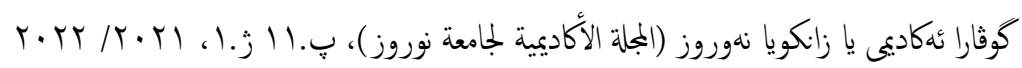

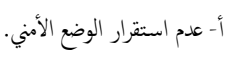

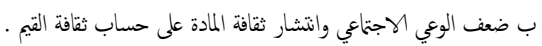

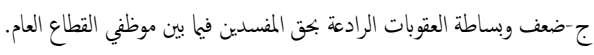
د- الافتقار إلى الثقافة الكافية في التعامل مع قضايا الفساد.

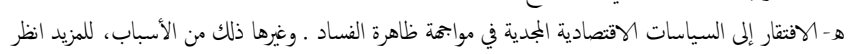

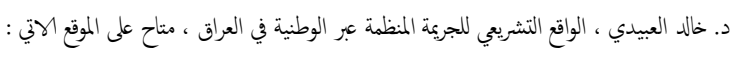
www.shared.com 31- د.قيس حسن عواد، الاقتزاض العام الخارجي وشروط مؤسسات التحويل الدولية، بجلة الرافدين للحقوق،

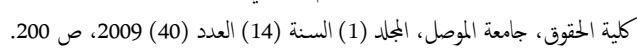

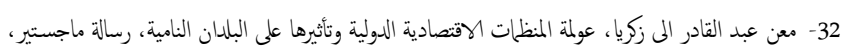

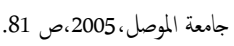

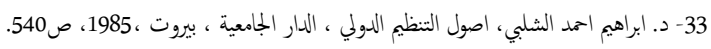

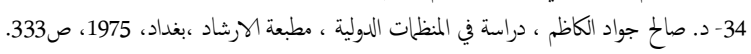

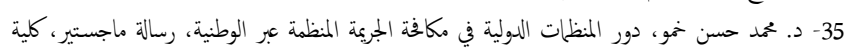

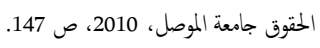

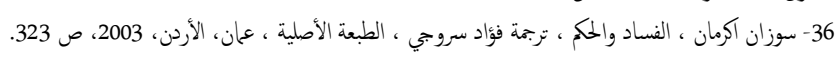

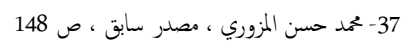

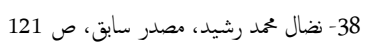

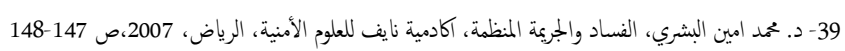

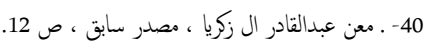

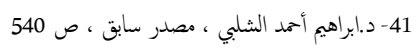

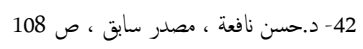

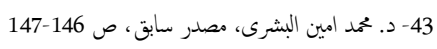

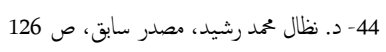

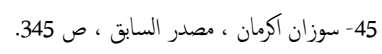

$$
\begin{aligned}
& \text { 46- نضال محمد رشيد، مصدر سابق، ص صدران ، } 126
\end{aligned}
$$

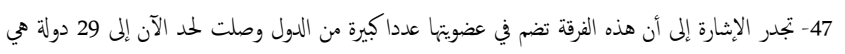

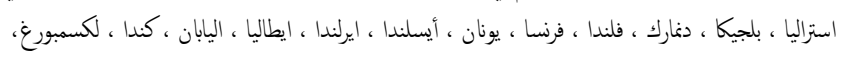

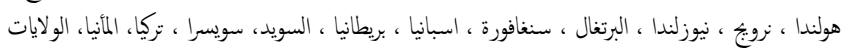

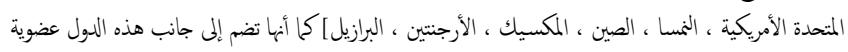

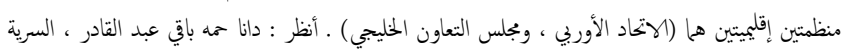

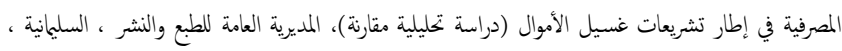

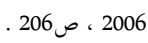

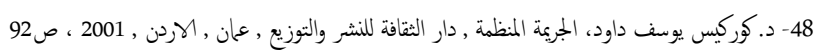

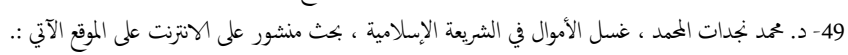
www.kantaksi.com تاريخ الزيارة 50- د. أجد سعود قطيفان ، جريمة غسيل الموال , دراسة مقارنة , دار الثقافة للنشر والتوزيع, عان , الأردن

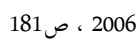
51- د. كركيس يوسف داود ، مصدر سابق ، ص 92006

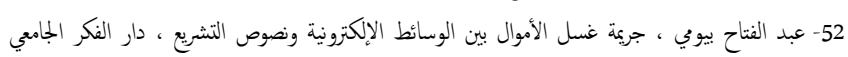

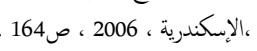

53- د. كوركيس يوسف ، المصدر السابق ، ص 93 54- د. بابكر الشيخ، اليات المجتع الدولي في التصدي لظاهرة غونسيل الأموال , مكتبة الحامد, عان , الوردن , 2003

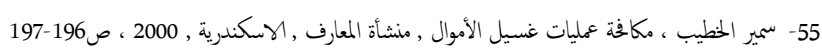

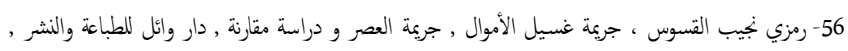

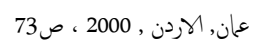

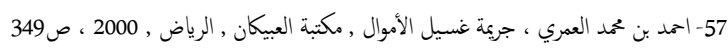

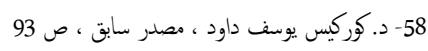

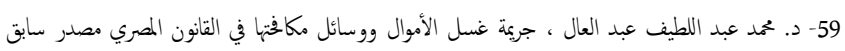
صن 60 - احمد بن محمد العمري ، مصدر سابق ، ص 350

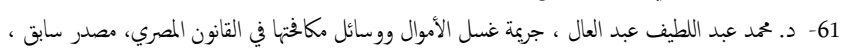
ص 198. 62- د. كوركيس يوسف داود ، المصدر السابق ، ص 94
5- د. صلاح الدين فهي محمود، الفساد الاداري كموق لعمليات التنمية الاجتاعية والاقتصادية، اكلديمة نايف الكاضي

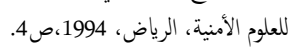

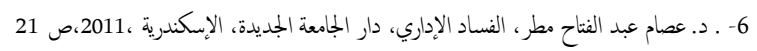

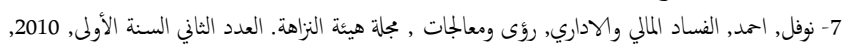
ص100. 8- د. حسن بو نغامة عبدالله, مكافة النساد, ج2, اكلديمية نايف للعلوم الأمنية, الرياض, 2003, ص

586_585

9- د. محمد جال باروت , الفساد والحكم الصاح في البلاد العربية , مركز الوحدة العربية , القاهرة , 2004, ص 18

10- نقلا عن سارة بور سعيود , دور استراتيجية مكافة الفساد الاقتصادي في تحقيق التنمية المستدامة , راسة

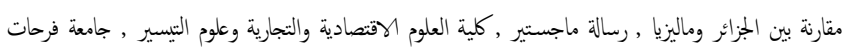
عباس سطيف , الجزائر , 2013 , صنائنا

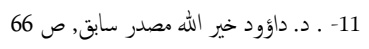
12- مصطنى حميد كزار , الفساد الاداري والمالي واعكاساته على البطالة في العراق , رسالة ماجستير , كلية

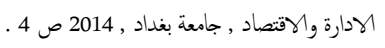
13- نظال محمد رشيد, دور المنظات الدولية في مكافة الفساد الاداري والمالي, رسالة ماجستير, كلية الحقوق

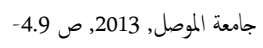
14-. د. محمود محمد معابرة, الفساد الاداري وعلاجه في الشريعة الإسلامية, ط1, دار الثمار الثقافة والنشر, عمان ,

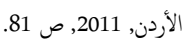

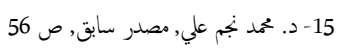

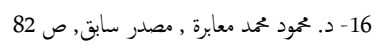

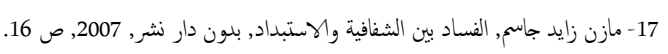

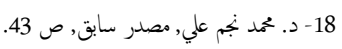

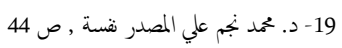

20- تجدر الاشارة الى انه هناك اسباب خاصة أدت إلى انتشار ظاهرة الفساد بكثرة في العراق وتتجسد

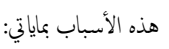
1. الحروب والصراعات والحصار , فالحروب المتعاقبة التي شنها النظام السابق وماتبعها من ظروف الحصار

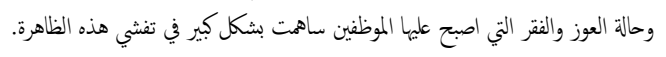
2. 2. انعدام العدالة الكجتاعية. 3. تياب الخاسبة والشفافية

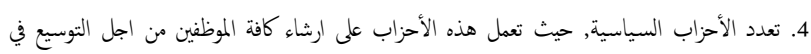

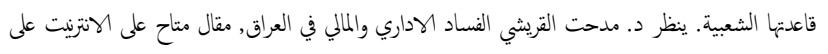

http1/iraqiconomists.net

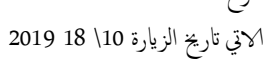

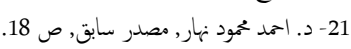

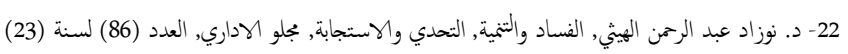

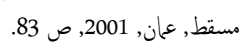

23 - د. احمد محمود نهار مصدر سابق, ص 19.

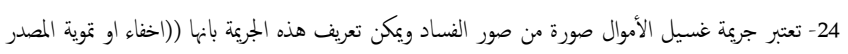

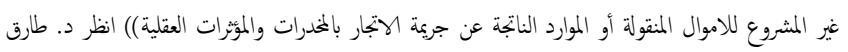

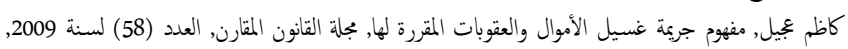
ص.31 25- د. فارس رشيد البياتي, الفساد الاداري والمالي في المؤسسات الإنتاجية والخدمية, دار ايلية للنشر والتوزيع, صائ

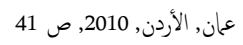
24- د. جال داؤود سليمان, الهار الاقتصادية والاجتاعية لظاهرة الفساد الاماري, المجلة الجامعية الخليجية, الجملد

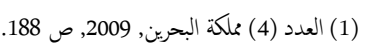
26- تجدر الاشارة الى انه هناك علاقة وثيقة بين الفساد والجريمة المنظمة والجريمة المنظمة هي الجريمة التي يتم

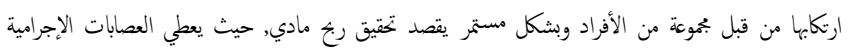

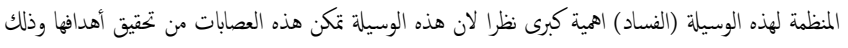

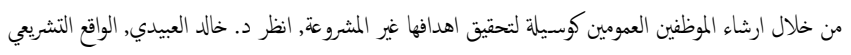

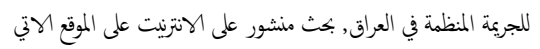

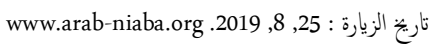
27- د. محمد نجم علي, مصدر سابق, ص 76

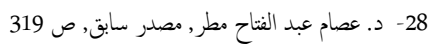

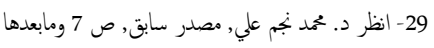
30- تجدر الاشارة الى أن أهم الأسباب التي أدت التي تفشي ظاهرة الفساد في العراق يككن تلخيصها بايائتي: 


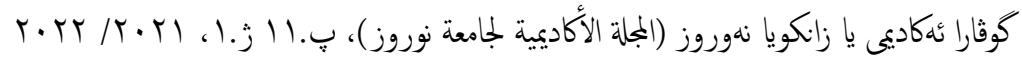
63- د. محمد عبد اللطيف عبد العال ، جريمة غسل الأموال ووسائل مكافتها في القانون المصري، مصدر س ابق

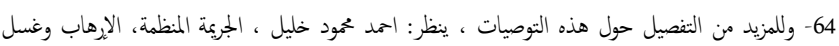

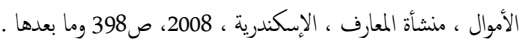

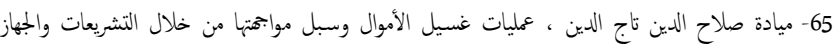

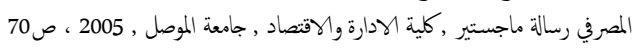

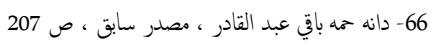

